\title{
Book Review - Food, Feminisms, Rhetorics, edited by Melissa A. Goldthwaite
}

\section{Sarah Moon-Massachusetts Maritime Acadamy}

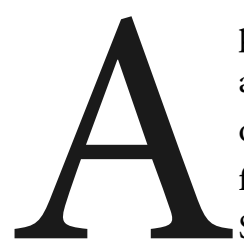

publication of Southern Illinois University Press's series Studies in Rhetorics and Feminisms, Food, Feminisms, Rhetorics, edited by Melissa A. Goldthwaite, offers readers a wide range of rhetorical analyses of food-related fiction, nonfiction, television, art, and commodities from a variety of feminist lenses. Some of the offerings are substantial and satisfying, while others only whet the appetite, but collectively this work succeeds in illustrating the considerable breadth of cultural terrain touched by questions of food and feminism. The essays in the first section show how cookbooks and recipes serve as revealing objects for feminist historiographical work; the second section provides a primer on important female food writers and other culture influencers; the third section shows that contemporary food movements, while seemingly progressive, are also in some cases challenging feminist progress; and the final section confronts the fact that, especially as women, we cannot talk about food without also talking about bodies. These chapters together pose a kairotic question about the rhetorical representation of women's relationship to food: What rhetoric around food and bodies is most authentically empowering to women?

The book's first section, "Purposeful Cooking: Recipes for Historiography, Thrift, and Peace," asserts that traditionally undervalued objects of research, cookbooks, and family recipes are fruitful materials for rhetorical analysis. Carrie Helms Tippen argues that cookbooks are important sites for doing feminist historiographical work, referencing the point of Janet Theophano in Eat My Words: Reading Women's Lives through the Cookbooks They Wrote that cookbooks are "among the few documents authored by and for women that were protected and 'passed down' as heirlooms" (17). Jennifer E. Courtney writes about the rhetoric of kitchen thrift from the early nineteenth century to the present, asserting that "[d] espite the identified dearth of scholarship on thrift . . kitchen thrift and discourses on kitchen thrift are alive and well, running parallel to and sometimes intersecting with mainstream consumer narratives" (51). Courtney briefly summarizes two books, a newsletter, a television show, and a blog, inspiring curiosity about this genre and ideas about how the rhetoric of thrift might intersect with the rhetoric of the contemporary local food movement. In "Promoting Peace, Subverting Domesticity: Cookbooks Against War, 1968-83," Abby Dubisar considers a more narrowly bounded set of texts to point out, significantly, that a feature of first-wave feminism was a rejection of having one's identity bound to traditional housewife duties like cooking. Cooking in the peace movement-based cookbook Peace de Resistance is framed as something to appease one's family so that a woman can then turn to her more important activist duties (68), while the 1973 cookbook Peacemeal frames cooking a bit differently, as "a necessary task to combat hunger and a way to 
gather people at the Greenwich Village Peace Center" (69). Peacemeal also positions cooking as nongender-specific and emphasizes how "food gatherings facilitate conversation" (70). In conclusion, Dubisar notes that the contemporary "new domesticity" movement makes a return to cooking its own revolution but that, as Emily Matchar has pointed out, baking your own bread and curing your own bacon is not "going to solve the world's problems"' (72). Dubisar poses a salient question for today's rapidly evolving food culture: "How can activists write cookbooks that resist industrial processing while also resisting gendered power dynamics that construct cooking as women's primary responsibility?" (72).

The book's second section turns to the realm of published and produced female food writing and television, starting with the foundational work of M.F.K. Fisher. For those unfamiliar with Fisher, Erin Branch provides an introduction, noting that Fisher's style and approach to food conflicted with the gender norms of the time. Editors of Fisher's first book Serve it Forth were surprised to find out she was a woman because her epicurean tone was considered male (78). Fisher, while employing a feminine writing style, notably bucked gender norms by emphasizing the pleasure and desire that attend eating. Branch analyzes Fisher's text for examples of a concept she terms "gastronomical kairos," revealing moments in which a feeling of life's importance and meaning is brought about through food (79). Branch articulates what may be so appealing about Fisher to those examining food and feminism now. For Fisher, pleasure was food's greatest purpose, and she vividly conveyed this pleasure in her writing.

Four of the five chapters in the book's third and most eclectic section, "Rhetorical Representations of Food-Related Practices," focus on representations of food and drink in fictional texts. However, the first chapter in the section, "Not Your Father's Family Farm: Toward Transformative Rhetorics of Food and Agriculture," focuses on the problematic symbolism of the family farm in "sustainable food movements" (121). Abby Wilkerson aims to contribute to Eileen Schell's call for an "alternative agrarian rhetoric" by considering the "potential of family rhetoric in movements for food justice and sustainability to reinforce existing social hierarchies and inequalities" (120-21). Wilkerson writes that on the surface, the family farm functions symbolically to represent a kind of "rehabilitative consumption, a voluntaristic sensibility that tells us if we just 'eat this, not that', we'll be saved" (122). Wilkerson's intervention is not to question the validity of the rehabilitative promise but to argue that the family farm does other symbolic work that comes "at great cost to women, people of color, and poor people" by connoting whiteness, heteronormativity and gendered roles (129). In contrast to the symbol of the heteronormative, white family farm, Wilkerson offers a portrait of the Farmway in Brightmoor, a twenty-two-block urban farm in a Detroit neighborhood comprising about thirty-five community gardens. Wilkerson wants to emphasize the significance of the ideological intervention of such projects over what they offer in terms of food access. She writes that such projects "generate spaces of conviviality and reciprocity ... across a range of cultural divides" and "create oppositional spaces where food becomes a channel for community building and generating resistance to entrenched power" (129). Wilkerson's argument feels fresh but also rhetorically actionable. Farmers' markets can choose to brand themselves as more in alignment with newer, non-traditional modes of farming as opposed to the traditional image of the family farm. 
The next three chapters in the section each look at the role of food in fiction as a conveyor of culture and gender norms. Concluding the third section, Tammie M. Kennedy's chapter "Boxed Wine Feminisms: The Rhetoric of Women's Wine Drinking in The Good Wife" looks at how "drinking practices function rhetorically" in the wider culture and then specifically in the television show The Good Wife. Kennedy asserts that "television representations normalize drinking wine as a way for women to navigate the tensions of their personal and professional choices" but calls into question what this normalization elides (182).

The book's final section, "Rhetorical Representations of Bodies and Cultures," begins with two chapters that look at highly specific representations of bodies within a cultural context, the images of Mexican women on Mexican food products and the artistic representations of Jewish women during the Holocaust. Goldthwaite compellingly chooses to conclude the book with a set of four chapters that present two opposing approaches to a feminist stance toward food and bodies. Rhetorical analyses of pro-anorexia websites in one chapter and the Skinny Bitch books in the next offer up a striking contrast with a chapter on the BBC's Two Fat Ladies cooking show of the late 1990s and the final chapter looking at detective novels featuring plus-size female private investigators. What these analyses do as a set is to illustrate that women are, first, longing to feel good about themselves, and, for many, that means revising the way they see their bodies and, accordingly, how they eat. And rhetoric plays a significant role in that "revision." On the far extreme of the food-control approach are pro-ana websites. Though author Morgan Gresham focuses on a now-defunct site called House of Thin which "seeks to provide a supportive environment for those who may wish to recover from an eating disorder," the chapter also serves to educate readers on the extreme conflation of identity with body size and eating habits that marks the pro-ana community, even those members who consider themselves "in recovery" (214). Gresham writes that House of Thin employs an "invitational rhetoric" that allows for those anywhere on the spectrum-from fully committed to pro-ana to those in recovery-to feel accepted there. Rebecca Ingalls looks at the Skinny Bitch books, which use what might be called the opposite of invitational rhetoric as the authors argue that cutting out meat, sugar, and overeating will yield a leaner, healthier, more ethical you. As Rebecca Ingalls shows, the authors' rhetorical style is borderline abusive, actively working to make readers feel guilty and disgusted by their current eating habits.

On the other hand, Two Fat Ladies, as Sara Hillin writes, celebrates taking unabashed pleasure in food and pushes back against 1990s cultural trends toward low-fat foods and vegetarianism. Hillin writes that the show's hosts made fatness "their rhetorical platform" and used it to further their project of "promoting more ethical manufacturing and sale of meats, educating oneself about health claims related to diet, and ending gender-based size discrimination" (247). Turning to fiction, Elizabeth Lowry shows how detective novels featuring plus-size female detectives "challenges stereotypes of fat people as being asexual or overly libidinous" (258). Lowry argues that fatness is often "negatively coded" as an "excess of femaleness" but that texts that show overweight women enjoying professional and personal success suggest we are moving past women feeling that they have to shed fat to be taken seriously (262).

The first two chapters in the book's final section show how rhetoric can be deployed to construe 
both thinness and fatness as empowering to women. Rebecca Ingalls shows how the author of Skinny Bitch leverages rhetoric around issues with food production and the power of controlling one's eating and body size to persuade readers to lose weight. Hillin, in contrast, shows how the hosts of Two Fat Ladies leverage rhetoric around the freedom of taking pleasure in food and resisting misogynist critique toward an embrace of fatness. These two polar approaches to empowerment through food help reveal the schizophrenic stance on food that permeates contemporary western culture. On the one hand, the Skinny Bitch, as Ingalls suggests, gains power by rejecting the cultural norm of eating meat and junk food; on the other hand, the Two Fat Ladies, as Hillin argues, gain power by rejecting the cultural norm of dieting and fat-shaming.

Two of the important questions the chapters in this collection raise are, What relationship(s) to food are authentically empowering to women? and, in turn, What rhetoric around food and bodies is most empowering to women? It is fascinating that the last four chapters present such polar attitudes about consumption and body shape being construed as empowering. What is shared, though, across these divergent positions is the link between the female body and female self-value. To encompass both perspectives, one could say that choosing how one eats and one's body shape-whatever that choice may be-is empowering for women.

After reading Food, Feminisms, Rhetorics, I am led to wonder about the ways that progressive shifts in food system rhetoric might intersect with progressive rhetoric around female bodies. I want to take Abby Wilkerson's argument about family farm rhetoric along with Abby Dubisar's analysis of the peace activism cookbooks and try to sync it with the message of M.F.K. Fisher and the rhetoric of Two Fat Ladies. Let growing food and cooking be as significant to communities and all the members within them as they have been to families and mothers. Let food be a pleasure. Let a diversity of body types be positively-coded female. Unshackle women from being walking testimonies to someone else's food values, scrutinized for how they do or do not cook and for how they appear to eat. Food, Feminisms, Rhetorics shows us that attending more consciously to our choice of words around farming, food packaging, cooking, and female bodies is essential to a cultural shift toward a more feminist conception of food. 
LiCS 8.1 / July 2020

\section{WORKS CITED}

Goldthwaite, Melissa A., editor. Food, Feminisms, Rhetorics. Southern Illinois UP, 2017. 